Tami Oliphant

University of Alberta, Edmonton, Alberta, Canada

\title{
Interpreting mediated quantitative data: Insights from information behaviour research
}

\begin{abstract}
Résumé:
Using climate change as an example, this conceptual paper explores two issues: the difficulties people have in understanding, interpreting, and responding to quantitative data, and the ways in which, if any, information behaviour research might provide insight into this issue. Data related to climate change were selected because they are often mediated by others with divergent vested interests including media, politicians, NGOs, scientists, and government agencies and because people bring a host of cognitive and psychological biases, worldviews, and beliefs to their perceptions of data and information and consequently, climate change.
\end{abstract}

\section{Introduction}

On January 25, 2018, the Bulletin of Atomic Scientists, which has been tracking the threat posed by nuclear weapons and other technologies since the $1940 \mathrm{~s}$, moved the doomsday clock two minutes closer to symbolic apocalyptic midnight, the closest the clock has ever been. In addition to the heightened threat of nuclear war, the doomsday clock was moved because of a lack of action on climate change, of which the Bulletin writes: "avoiding catastrophic temperature increases in the long run requires urgent action now" (Mecklin 2018). Climate change is a "wicked problem"-a social or cultural problem that is difficult or impossible to solve for a number of reasons such as incomplete or contradictory knowledge, the number of people and opinions involved, the large economic burden to address the problem, and the interconnected nature of wicked problems with other problems (Rittel and Webber 1973). Furthermore, most urban dwellers lack a connection to the land and access to environmental feedback and consequently rely on external information sources for information about sustainability and climate change (Isenhour 2011).

While there are many cultural, economic, and social reasons for collective inertia regarding taking action on climate change, not much attention has been paid to the issue from an LIS (library and information studies) perspective. There are a number of characteristics about quantitative data, and climate data in particular, that are of interest to LIS researchers. Climate data is complex and requires mediation. Members of the general public do not typically seek out climate data of their own volition. People who interpret, mediate, and communicate this data such as politicians, media, NGOs, scientists, and governments often have vested interests in the content, framing, and communication of these messages. Consequently, media narratives and reports and the ways in which scientific data and research are communicated are powerful forces in shaping people's perceptions about climate change. Furthermore, interdisciplinary work has explored how humans process and interpret quantitative data and information with particular attention paid to human fallibility regarding innumeracy ("an inability to deal comfortably with the fundamental notions of number and chance" (Paulos 2001, 1)), our inability to respond emotionally to large numbers (and bad news), and our general lack of understanding of science and knowledge production. Finally, social and cultural constructions of worldviews, beliefs and ideology powerfully influence how we interpret 
data, information, and science. These social, cultural, psychological, and cognitive biases have contributed to individual and social inaction about climate change. Drawing on a wide number of fields such as psychology, library and information studies (LIS), and critical data studies, this conceptual paper explores the following two questions:

1) In what ways do people have difficulty interpreting, understanding, and acting upon mediated quantitative data?

2) What insights, if any, can be gleaned from information behaviour research regarding how people interact with, interpret, and understand quantitative data?

The answers to these questions have potentially significant implications for LIS professionals and researchers in terms of social justice, promoting data for the public good, encouraging community-based work and activism, and communicating climate change data and information to the general public.

\section{Methodology}

The literature from information behaviour research, critical data studies, psychology, and communication studies among others was systematically searched, analyzed, and synthesized in order to identify some of the reasons why quantitative data is difficult for people to interpret, understand, and more importantly, to respond to. To answer the second research question, relevant aspects of the information behaviour research literature were identified that may assist in developing our understanding of the intersections among data, information, and mediation in addition to identifying areas for future research for information behaviour scholars in the realm of data and information processing or information use.

\section{Interpreting and understanding quantitative data}

Annie Dillard (1990) powerfully illustrates the struggle in finding meaning (and empathy) when we are confronted by large numbers:

There are 1,198,500,000 people alive right now in China. To get a feel for what this means, simply take yourself in all of your singularity, importance, and complexity, and love - and multiply by $1,198,500,000$. See? Nothing to it.

This quotation highlights the cognitive and psychological difficulties that human beings have making meaning from, and acting upon, quantitative data. Two issues are at play: we are increasingly awash in data and information and at the same time "the human mind is quickly desensitized by information presented in the form of quantitative numbers" (Slovic and Slovic 2015). In the book Numbers and Nerves, a series of contributors investigate a number of psychological issues that humans have that inhibits their ability to comprehend and act on numbers including "psychic numbing" (as numbers get larger and larger, we become insensitive because the number fails to trigger the emotion or feeling necessary to motivate action" [p. 27]), the power of one (the power of an individual case), and pseudo-inefficiency ("we find that people often feel less good about helping those they can help, and they help less, when their attention is drawn to those they can't help" (p. 43). In this regard, our cognitive biases, values, and affect play 
significant roles in data interpretation, processing, data use, and our subsequent behaviour.

In addition to our psychological biases, the ontological and epistemological status of data influence how data are perceived and treated. For example, Rosenberg argues that data have "no ontological truth" because false data are data nonetheless. Data are socially constructed and "do not exist independently of ideas, techniques, technologies, systems, people and contexts" (Kitchin 2014). They are not neutral or objective; they are partial representations and as such they are reductionist and open to a wide range of interpretation. Furthermore, in LIS, data are often conceived as becoming information when meaning is ascribed to them. Where information is context-bound, data are not necessarily. These two aspects of data-our cognitive and psychological responses and the epistemological and ontological status of data - are central to understanding why interpreting mediated climate data and responding to it, is difficult.

\section{Information behaviour research}

Historically, much of the information-seeking literature has been "concerned with practical issues regarding the stages, mechanisms, processes, channels, sources, and sometimes the barriers that mediate information seeking" (Case, Andrews, Johnson and Allard 2005, 356). More recently, Choo (2017) offered nine propositions for studying information seeking and avoiding in his study "Seeking and Avoiding Information in a Risky World." Choo focuses on risk and climate change and presents the concept of information processing which "refers to the use of the information that has been found or encountered, and it includes analyzing, evaluating, interpreting, and making sense of the information acquired" and is distinct from information seeking. Furthermore, the prominence of "fake news" has brought the role of internal conditions and biases that people bring to information interactions to the fore (Day 2017). At the same time, in terms of data science, LIS research and practice has focused on data curation, preservation, access, visualization, organization, and re-use and has not paid as much attention to how people process, interact with, and make meaning from data including mediated data. Information behaviour research and critical data studies have much potential in this regard.

\section{Discussion and Conclusion}

While there are multi-faceted reasons why people are unresponsive to climate change (Marshall 2014), when considered within the context of quantitative data several reasons are prominent: psychic numbing, innumeracy, pseudo efficiency, mediation, and the need to "trust the messenger more than the message." Furthermore, the cognitive and psychological biases, beliefs, values, and worldviews that each of us brings to information interactions exert great influence on our information behaviour and our interpretation of data. There is also value in exploring information processing as something distinguishable from information seeking, information retrieval, and which may provide insight into information use.

Finally, as Malm and Hornberg (2014) note, climate change is a social justice issue with effects that are, and will be, felt more keenly by some more than others. We are a narrative species as well as a species who are analytical and value measurement. We need both story, numbers, analysis, and measurement in order to make sense of the world. Communicating mediated quantitative data in the form of narratives about climate change 
are of paramount importance as climate change ultimately affects not only all of humankind, but the future viability of every single non-human species on the planet.

\section{Reference List:}

Case, D., Andrews, J. E., Johnson, D. J., and Allard, S. (2005). “Avoiding versus seeking: The relationship of information seeking to avoidance, blunting, coping, dissonance, and related concepts." Journal of the Medical Library Association, 93(3), 353-362.

Choo, C. W. (2017). "Seeking and avoiding information in a risky world." Information Research, 22(3), paper 765. Retrieved from http://InformationR.net/ir/223/paper765.html

Day, R. (2017). Before Information Literacy [Or, Who Am I, As a Subject-Of(Information)-Need?]. 80th Annual Meeting of the Association for Information Science \& Technology, Washington, DC | Oct. 27-Nov. 1, 2017

Dillard, A. (1999). For the time being. New York: Alfred A. Knopf.

Isenhour, C. (2011). "How the grass became greener in the city: On urban imaginings and practices of sustainable living in Sweden." City \& Society, 23(2), 117-134.

Kitchin, R. (2014). The Data Revolution: Big Data, Open Data, Data Infrastructures \& Their Consequences. London: Sage Publications.

Malm, A. and Hornberg, A. (2014). The geology of mankind? A critique of the Anthropocene narrative. The Anthropocene Review, 1(1), 62-69.

Marshall, G. (2014). Don't even think about it: Why our brains are wired to ignore climate change. London, UK: Bloomsbury.

Mecklin, J. (2018). (Ed.). "It is now two minutes to midnight. 2018 Doomsday Clock Statement Science and Security Board." Bulletin of the Atomic Scientists. Retrieved from https://thebulletin.org/2018-doomsday-clock-statement

Paulos, J. P. (2001). Innumeracy: Mathematical illiteracy and its consequences. New York: Hill and Wang.

Rittel, H., and Webber, M. (1973). "Dilemmas in a general theory of planning" Policy Sciences, 4(2), 155-69.

Slovic, S. and Slovic, P. (Eds.). (2015). Numbers and Nerves: Information, emotion, and meaning in a world of data. Corvalis, OR: Oregon University Press. 